\title{
Espiritualidade como acesso à verdade: uma provocação de Michel Foucault para a Teologia
}

\author{
Spirituality as access to truth: a provocation of Michel Foucault for Theology
}

Irenio Silveira Chaves*

\begin{abstract}
Resumo
O presente artigo tem por objetivo fazer uma análise do tema do acesso à verdade e da espiritualidade nas obras de Michel Foucault em sua última fase, tendo em vista suas implicações para a construção do discurso teológico. A preocupação será identificar em que medida é possível empreender um saber teológico tendo como pressupostos as investigações de Foucault sobre o cuidado de si. Os temas que envolvem o acesso à verdade e a espiritualidade no pensamento foucaultiano possibilitam uma transversalidade com os modos de construção do saber teológico, sobretudo pelo fato de que o cristianismo e a teologia ocidental se apropriaram das técnicas de si engendradas no período grecoromano, que resultou nas formas de pensamento a respeito da subjetividade engendradas na modernidade. A identificação desse campo de investigação permite à teologia um novo caminho para o diálogo contemporâneo e para uma revisão dos modos de afirmação de uma ação pastoral voltada para a condição humana em sua realidade vivencial.
\end{abstract}

Palavras-chave: verdade; espiritualidade; subjetividade; teologia; filosofia.

\begin{abstract}
This article aims to analyze the issue of access to truth and spirituality in the works of Michel Foucault in his last phase, given its implications for the construction of theological discourse. The concern is to identify to what extent it is possible to undertake a theological knowledge with presuppositions as investigations of Foucault on care of the self. The issues surrounding the access to truth and spirituality in Foucault's thinking provides a transversal with the way of construction of theological knowledge, especially by the fact that Christianity and Western theology appropriated the techniques of the self in the Greco-Roman period, which resulted in ways of thinking about subjectivity in modernity. The identification of this field of research enables Theology a new way to for contemporary dialogue and a review of the ways of asserting a pastoral action towards human condition in its experiential reality.
\end{abstract}

Keywords: true; spirituality; subjectivity; theology; philosophy.

Artigo recebido em 12 de maio de 2014 e aprovado em 24 de Setembro de 2014.

* Doutor em Teologia. Professor na Pontifía Universidade Católica do Rio de Janeiro (PUC/RJ). País de origem: Brail. E-mail: ireniochaves@uol.com.br. 


\section{Introdução}

A partir das obras de Michel Foucault em sua última fase, é possível problematizar sobre a compreensão das relações intersubjetivas e as estratégias para a construção do sujeito capazes de fazer com que este resista aos modos de sujeição que lhe são impostos. Isso está implicado no campo da cultura de si, da subjetivação e da afirmação de si como sujeito do conhecimento, levada a efeito no que podemos denominar de "último Foucault". Para efeito de definição do seu pensamento nessa última fase, deve ser incluída a trilogia ligada à História da Sexualidade, em que Foucault desenvolve seus estudos sobre os processos de subjetivação desde a filosofia dos séculos I e II da era cristã. Além disso, dentre as conferências levadas a efeito na década de 1980 (até a sua morte em 1984), destaca-se $A$ hermenêutica do sujeito, onde se encontra sua principal abordagem sobre a relação entre espiritualidade e acesso a verdade.

Para este artigo, a preocupação será de identificar o acesso à verdade como um tema pertinente no pensamento foucaultiano, que acaba se constituindo como o objetivo central de toda a sua investigação. Foucault entende que esse tema, inclusive no âmbito da espiritualidade, envolve o aspecto arqueológico da formação da cultura ocidental moderna e, por essa razão, empreende uma análise sobre os exercícios espirituais no período helênico (séculos I e II) e no pensamento dos padres da igreja (séculos II e III). É possível identificar, nesses estudos, uma transversalidade com a Teologia na medida em que põe em questão o discurso teológico e o modo como este se apropriou das técnicas de si para engendrar um movimento contínuo de construção da verdade.

É preciso que se diga que Foucault nunca quis fazer Teologia. É preciso que se defina também que Foucault não trata da espiritualidade no âmbito da teologia, mas da forma com que o pensamento helênico a concebeu, abrangendo as ideias que levaram à noção dos exercícios espirituais, do que posteriormente o cristianismo veio se apropriar. Entretanto, o diálogo teológico com o pensamento 
de Foucault torna-se possível em face do interesse da teologia contemporânea em dialogar com a cultura e as formas com que se configuram os saberes nas relações da sociedade. A intenção de aproximar o pensamento foucaultiano com a Teologia envolve a proposta geral de aproximação entre Teologia e Filosofia, cujo interesse específico é de identificar como os saberes são construídos e como acontecem as condições de produção do conhecimento, a fim de que se promova uma visão crítica da realização do conhecimento teológico.

\section{0 tema do acesso à verdade}

A preocupação de Foucault ao tratar da temática da subjetividade é, em última análise, verificar a relação possível entre sujeito e verdade. Com a História da loucura, já em 1961, ele identifica um campo de investigação das experiências em que uma cultura expõe valores que lhes são característicos. Isso desperta o interesse pelo surgimento do que poderia se chamar de "o homem verdadeiro". Ao analisar essa primeira atitude, Alexandre Filordi de Carvalho reconhece que, no trabalho de Foucault, há um interesse no fato de que "as percepções da loucura que vão se modificando também alteram a relação do homem com a verdade até chegar ao ponto em que, por não ser mais o louco considerado insano, mas alienado, aquele que, sendo o que é, carrega um outro" (CARVALHO, 2007, p. 35). Implica que:

[...] o homem não é mais considerado numa espécie de recuo absoluto em relação à verdade; ele é, aí, sua verdade e o contrário de sua verdade; é ele mesmo e outra coisa que não ele mesmo; é considerado na objetividade do verdadeiro, mas é verdadeira subjetividade; está mergulhado naquilo que é sua perdição, mas só entrega aquilo que quiser entregar; é inocente porque não é aquilo que é, e culpado por ser aquilo que não é. (FOUCAULT, 1978, p. 573).

É isso que remete à compreensão que norteará o entendimento sobre a verdade no último Foucault, cujas bases foram lançadas desde o início. Esse modo de ver é que permite notar que “o ser humano não se caracteriza por um certo relacionamento com a verdade, mas detém, como pertencente a ele de fato, 
simultaneamente ofertada e ocultada, uma verdade” (FOUCAULT, 1978, p. 575). Pertencer a uma verdade corresponde a estar inserido em um certo ordenamento, numa rede de saberes, num espaço histórico que permite que se estabeleça um modo de ser que pode se tornar conhecido e pensado.

$\mathrm{Na}$ aula inaugural do Collège de France, em 1970, Foucault faz uma distinção entre verdade e vontade de verdade, na medida em que a verdade tenha se deslocado, ainda na antiguidade grega, do ato de enunciação para o próprio enunciado, como um critério que permite distinguir o verdadeiro do falso.

Como se poderia razoavelmente comparar a força da verdade com separações que, de saída, são arbitrárias, ou que ao menos, se organizam em torno de contingências históricas; que não são apenas modificáveis, mas estão em perpétuo deslocamento; que são sustentadas por todo um sistema de instituições que as impõem e reconduzem; enfim, que não se exercem sem pressão, nem sem ao menos uma parte de violência. (FOUCAULT, 2005, p. 13-14).

Jürgen Habermas entende que a verdade para Foucault é "um pérfido mecanismo de exclusão já que só funciona sob a condição de permanecer oculta a vontade de verdade que nele se impõe em cada caso" (HABERMAS, 2002, p. 347). Os critérios de validade que fazem a distinção entre verdadeiro e falso se baseiam em regras que estão subjacentes e que constituem o discurso. Diz Habermas: “As próprias estruturas que possibilitam a verdade não podem ser verdadeiras ou falsas, de modo que só é possível perguntar pela função da vontade expressa nelas, assim como pela genealogia dessa vontade com base em um plexo de práticas de poder" (HABERMAS, 2002, p. 348).

Foucault se apropria da noção de vontade de verdade de Nietzsche, em que a legitimação do discurso da ciência ou mesmo a pretensão de uma cientificidade se dá por meio de um controle. "Essa incondicionada vontade de verdade: o que é ela?”, indaga Nietzsche. “É a vontade de não se deixar enganar? É a vontade de não enganar? Pois também desta última maneira poderia ser interpretada a vontade de verdade: pressuposto que sob a generalização 'eu não quero enganar' esteja 
incluído também o caso particular 'eu não quero me enganar”” (NIETZSCHE, 1983, p. 212). Mais adiante, Nietzsche dirá: “consequentemente, 'vontade de verdade’ não quer dizer 'eu não quero me deixar enganar', mas sim - não há nenhuma escolha 'eu não quero enganar, nem sequer a mim mesmo': - e com isso estamos no terreno da moral” (NIETZSCHE, 1983, 213).

Para Foucault, no entanto, essa vontade de verdade tende a exercer uma espécie de pressão e uma forma de coerção sobre os outros discursos, responsável pela separação entre o verdadeiro e o falso e que assume os procedimentos de exclusão. Ele diz que é "como se para nós a vontade e suas peripécias fossem mascaradas pela própria verdade em seu desenrolar necessário" (FOUCAULT, 2005, p. 19-20). Nesse sentido, “o discurso verdadeiro, que a necessidade de sua forma liberta do desejo e libera do poder, não pode reconhecer a vontade de verdade que o atravessa; e a vontade de verdade, essa que se impõe a nós há bastante tempo, é tal que a verdade que ela quer não pode deixar de mascará-la” (FOUCAULT, 2005, p. 20). Ou seja, o verdadeiro não se define pela conformidade com uma coisa nem com a correspondência entre duas coisas, mas por uma ordem que se apresenta nas coisas como uma lei interior e que emerge a partir de um olhar e de uma enunciação. ${ }^{1}$ Dito de outro modo: "A verdade está no discurso, e não no homem, porquanto este emerge na historicidade do próprio discurso" (CANDIOTTO, 2010, p. 29).

Isso implica dizer que o problema da verdade é tratado a partir do modo como a subjetivação é problematizada. Deleuze registra que:

[...] O uso dos prazeres tira a conclusão de todos os livros precedentes quando mostra que o verdadeiro só se dá ao saber através de "problematizações" e que as problematizações só se criam a partir de "práticas", práticas de ver e práticas de dizer. Essas práticas, o processus e o procedimento constituem o processo do verdadeiro, "uma história da verdade”. (DELEUZE, 2005, p. 73).

\footnotetext{
1 "A ordem é ao mesmo tempo aquilo que se oferece nas coisas como sua lei interior, a rede secreta segundo a qual elas se olham de algum modo umas às outras e aquilo que só existe através do crivo de um olhar, de uma atenção, de uma linguagem." (FOUCAULT, 2002. p. XVI).
} 
Para Foucault, a verdade não existe fora de uma relação de poder. "A verdade é deste mundo; ela é produzida nele graças a múltiplas coerções e nele produz efeitos regulamentados de poder" (FOUCAULT, 1995, p. 12). ${ }^{2}$ Diz respeito a um regime de verdade que cada sociedade mantém, um conjunto de procedimentos que são regulados para a vida em sociedade, que orientam a formação dos discursos, os mecanismos de controle que identificam o verdadeiro, os procedimentos que permitem o acesso à verdade e o que define quem tem a capacidade de dizer o que é verdadeiro.

[...] a "verdade" é centrada na forma de discurso científico e nas instituições que o produzem; está submetida a uma constante incitação econômica e política (necessidade de verdade tanto para produção econômica, quanto para o poder político); é objeto, de várias formas, de uma imensa difusão e de um imenso consumo (circula nos aparelhos de educação ou de informação, cuja extensão no corpo social é relativamente grande, não obstante algumas limitações rigorosas); é produzida e transmitida sob o controle, não exclusivo, mas dominante, de alguns grandes aparelhos políticos ou econômicos (universidade, exército, escritura, meios de comunicação); enfim, é objeto de debate político e de confronto social (as lutas "ideológicas"). (FOUCAULT, 1995, p. 13).

O que Foucault entende por verdade, portanto, refere-se a um conjunto de procedimentos que se encontram regulados para a produção, ordenamento, circulação e funcionamento de enunciados. "A verdade está circularmente ligada a sistemas de poder que a produzem e a apoiam, e a efeitos de poder que ela induz e que a reproduzem" (FOUCAULT, 1995, p. 14).

Em sua última fase, Foucault está empenhado em descobrir de que maneira um saber se constitui e quais as relações que o pensamento mantém com a verdade. Ele dirá: "O que procuro fazer é a história das relações que o pensamento mantém com a verdade; a história do pensamento, uma vez que ela é pensamento sobre a verdade" (FOUCAULT, 2006, p. 241).3 E isso ele fez através da problematização da subjetividade como um conjunto de práticas discursivas e não discursivas que

\footnotetext{
${ }^{2}$ Entrevista publicada inicialmente em 1977.

${ }^{3}$ Entrevista publicada inicialmente em maio de 1984.
} 
permite que uma coisa entre em um jogo de verdade e se constitua como objeto para o pensamento.

Ao investigar os modos como o sujeito entra em um determinado jogo de verdade, Foucault aborda a questão do saber-poder a partir de instrumentos que permitem que os sujeitos se constituam, que são as práticas de si, o que chama de jogos de verdade. Como o sujeito não é uma substância, mas uma forma que se constitui a partir de relações e interferências, Foucault está interessado em como diferentes formas de sujeito são construídas historicamente em relação aos jogos de verdade. Uma vez que as relações de poder estão presentes em todo o campo social e que há ainda estados de dominação, Foucault percebe que sempre há possibilidades de liberdade e de resistência.

As práticas não são coisas que o indivíduo invente, mas "são esquemas que ele encontra em sua cultura e que lhe são propostos, sugeridos, impostos por sua cultura, sua sociedade e seu grupo social” (FOUCAULT, 2006, p. 276). São esquemas prontos, inseridos nas relações humanas - que é no que consiste de fato as relações de poder -, que envolvem as ações que cada um procura exercer para dirigir sua própria conduta e a conduta do outro. Para que haja uma relação de poder e não uma relação de dominação, é preciso que haja, de um lado, formas de liberdade e, de outro, possibilidades de resistência.

Os jogos de verdade, por sua vez, estão relacionados a um conjunto de regras de produção da verdade, que são procedimentos que conduzem a resultados que podem ser verdadeiros ou falsos, válidos ou não, ganhos ou perdas, em função dos próprios princípios ou regras. Há jogos de verdade que visam à construção de uma verdade e há aqueles que visam a uma descrição. Sendo assim, quem diz a verdade? "Indivíduos que são livres, que organizam um certo consenso e se encontram inseridos em uma certa rede de práticas de poder e de instituições coercitivas" (FOUCAULT, 2006, p. 283). Aquele que tem a possibilidade de formular a verdade tem também o poder de expressá-la como quiser. 
Dentre as práticas e exercícios que possibilitam o acesso à verdade, alguns chamam a atenção de Foucault. Em conferência proferida em 1978 - cujo tema ficou conhecido pela pergunta: o que é a crítica? - reconhece que a modernidade inaugurou "uma certa maneira de pensar, de dizer, de agir igualmente, uma certa relação com o que existe, com o que se sabe, o que se faz, uma relação com a sociedade, com a cultura, uma relação com os outros também, e que se poderia chamar, digamos, de atitude crítica” (FOUCAULT, 1990, p. 36).

O que chama de atitude crítica consiste numa prática ou uma virtude que se relaciona diretamente com a verdade enquanto um devir. O papel da crítica tem a função de análise das condições de exercício da razão e de definição do presente a que se pertence. Isso leva à consideração de que:

Estamos na era de uma racionalidade dividida, fendida, de certo modo por dentro: cada vez mais totalizante, mas constantemente confrontada com o intotalizável (este é o paradoxo liberal). Daí a possibilidade de novas formas de luta. A crítica é igualmente, com efeito - é seu terceiro sentido - a experiência permanente de ultrapassagem, que precisa ser reencenada, das linhas de crise que atravessam um sistema (suas fronteiras). (SENELLART, 1995).

Ele procura entender essa atitude a partir do que chamou de pastoral cristã: um conjunto de ações empreendidas pela igreja que permitem que cada indivíduo seja governado ou conduzido no que diz respeito à salvação, o que demandaria a obediência como exigência.

Esta operação de direcionamento à salvação numa relação de obediência a alguém deve se fazer numa tripla relação com a verdade: verdade entendida como dogma; verdade também na medida em que esse direcionamento implica um certo modo de conhecimento particular e individualizante dos indivíduos; e, enfim, na medida em que esse direcionamento se desdobra como uma técnica reflexiva comportando regras gerais, conhecimentos particulares, preceitos, métodos de exame, confissões, entrevista etc. (FOUCAULT, 1990, p. 37).

Tratava-se de uma arte de governar os homens que conferia uma direção da consciência. Essa prática sofreu um deslocamento do foco religioso para domínios 
diversos, incluindo aí desde a arte de governar a família, até mesmo a arte de governar o corpo, o Estado etc. Essa governamentabilidade é que despertará uma outra questão: como não ser governado? Esse movimento é o que dá lugar, no limiar dos séculos XVI e XVII ao que pode chamar de atitude crítica: "a arte de não ser de tal forma governado" (FOUCAULT, 1990, p. 39). Foi isso que deu lugar a um conjunto de articulações que suscitaram o desenvolvimento de reflexões e de metodologias e que resultaram no modo em que se passou a tratar da relação entre poder, verdade e sujeito.

E se a governamentabilidade é mesmo esse movimento pelo qual se tratasse na realidade mesma de uma prática social de sujeitar os indivíduos por mecanismos de poder que reclamam de uma verdade, pois bem, eu diria que a crítica é o movimento pelo qual o sujeito se dá o direito de interrogar a verdade sobre seus efeitos de poder e o poder sobre seus discursos de verdade; pois bem, a crítica será a arte da não servidão voluntária, aquela da indocilidade refletida. A crítica teria essencialmente por função o desassujeitamento no jogo do que se poderia chamar, em uma palavra, a política da verdade. (FOUCAULT, 1990, p. 41)

Foucault procurou entender a proposta de Kant para que a humanidade chegue a sua idade adulta. É pela coragem de não se deixar ser dirigido por um outro que lhe diz "obedeça” que se descobre o princípio da autonomia, em que o sentido de obedecer está fundado nessa mesma autonomia, uma coragem de saber que consiste em reconhecer os limites do conhecimento. Uma autonomia que traz em si mesma a ideia da obediência. O tema da governamentabilidade será retomado mais tarde no último curso que ministrou no Collège de France, de 1983 a 1984: A coragem da verdade (FOUCAULT, 2009; ou 2011).

Essa preocupação também esteve presente no curso ministrado entre 1979 e 1980, O governo dos vivos, (FOUCAULT, 1977), quando procurou aprofundar a noção de governo como um conjunto de técnicas e procedimentos que foram usados para dirigir a conduta das pessoas a partir das práticas de exame de consciência e de confissão. O cristianismo primitivo reconheceu a confissão de pecado como um "ato de verdade”. Nesse curso, Foucault identifica dois conceitos relacionados a essas práticas: o primeiro é o que denominou de exomologese, que é 
uma espécie de ritual através do qual visava manifestar uma verdade e a adesão do sujeito a essa verdade; o segundo foi chamado de exagoreusis, que é o modo como se estabelecia a relação entre o crente e o confessor, a maneira de conduzir o exame de consciência e a responsabilidade de se declarar os movimentos do pensamento em sua totalidade. A finalidade é aprender os caminhos que o pensamento percorre para, assim, descobrir sua origem e orientar as decisões a serem tomadas, cujo foco é a vida contemplativa.

A obediência incondicional, o exame ininterrupto e a confissão exaustiva formam, portanto, um conjunto onde cada elemento implica os dois outros; a manifestação verbal da verdade que se esconde no fundo de si mesma aparece como uma peça indispensável ao governo dos homens uns pelos outros, tal como foi realizado nas instituições monásticas. (FOUCAULT, 1997, p. 105).

Foucault não esteve preocupado em empreender uma história da verdade, assim como não quis fazer uma história do sujeito, nem mesmo uma teoria da verdade ou do sujeito, mas ele sempre esteve preocupado em saber em que medida aquilo que o sujeito diz pode ser inscrito em categorias de verdadeiro ou falso, quais os jogos de verdade presentes nos modos de subjetivação que validaram alguns saberes e desprezaram outros. Nesse sentido, a verdade não será vista como um direito dado ao sujeito, mas implicará o acesso a ela a partir de exercícios e práticas inseridos na dinâmica da vida social.

\section{O tema da espiritualidade}

Foucault está preocupado em investigar de que maneira a relação entre sujeito e verdade foi articulada historicamente. Ele delimita, para isso, um campo conceitual: o cuidado de si, a preocupação consigo mesmo - o epiméleiaheautoû -, e o faz em uma oposição até mesmo à tradição filosófica, que vê no conhecimento de si - o gnôthiseautón - uma fórmula fundadora da relação entre sujeito e verdade. Embora Epicteto já tenha afirmado que o conhecimento de si está inscrito 
no centro da comunidade humana, 4 esse preceito aparece em alguns textos filosóficos, principalmente a partir de Xenofonte e Platão, como uma espécie de subordinação ao cuidado de si. A proposta, então, é de conceber o cuidado de si como “o momento do primeiro despertar", a base para que todo homem ocupe-se com sua alma. "O cuidado de si é uma espécie de aguilhão que deve ser implantado na carne dos homens, cravado na sua existência, e constitui o princípio da agitação, um princípio de movimento, um princípio de permanente inquietude no curso da existência” (FOUCAULT, 2004, p. 11).

Trata-se, portanto, de um princípio que norteia toda a conduta racional do período helenístico como um "fenômeno cultural de conjunto", que constitui um momento decisivo na história do pensamento que afeta, inclusive, a compreensão do modo de ser do sujeito moderno. Epiméleiaeautou corresponde: (a) a uma atitude do sujeito para consigo, para com os outros e para com o mundo; (b) a uma certa forma de olhar que implica uma conversão a si e a uma atenção ao seu próprio pensamento; (c) às ações e às práticas exercidas por si para consigo mesmo no sentido de efetivar mudanças e transformações no âmbito da espiritualidade.

[...] com a noção de epiméleiaeautou, temos todo um corpus definindo uma maneira de ser, uma atitude, formas de reflexão, práticas que constituem uma espécie de fenômeno extremamente importante, não somente na história das noções e das teorias, mas na própria história da subjetividade ou, se quisermos, na história das práticas da subjetividade. (FOUCAULT, 2004, p.15)5.

A preocupação com o cuidado de si na antiguidade remete a uma forma positiva de se estabelecer um fundamento para a moral. 6 As regras que resultam dessa compreensão foram sendo atualizadas e transferidas para um contexto novo, dentro do cristianismo e da modernidade, como uma ética geral e uma obrigação

\footnotetext{
${ }^{4}$ Foucault faz uma referência a estudos sobre os preceitos délficos: nada em demasia - medenagan -, as cauções - engye - e o conhecimento de si-gnothiseauton. Esses preceitos eram endereçados àqueles que vinham ao templo de Apolo, na cidade grega de Delfos, consultar o deus a fim de lembrar regras e recomendações relacionadas à maneira de se conduzir. Para Foucault, o preceito do conhecimento de si servia para que as pessoas se lembrassem de que "é-se somente um mortal e não um deus, devendo-se, pois, não contar demais com sua própria força nem afrontar-se com as potências que são as da divindade". (FOUCAULT, 2004, p. 6).

${ }^{5}$ Idem, p. 15. Para Foucault, "seria um erro acreditar que o cuidado de si foi uma invenção do pensamento filosófico e que constituiu um preceito próprio à vida filosófica. Era, de fato, um preceito de vida, de um modo geral altamente valorizado na Grécia". Resumos dos Cursos do Collège de France (1970-1982), p. 121.

${ }^{6}$ Para Foucault, ocupar-se consigo mesmo é ocupar-se com a casa e com a cidade, seguindo critérios da tradição filosófica grega. Cf. FOUCAULT, 2004, p.15.
} 
de cuidado com o outro. O tema do cuidado de si foi sendo substituído pela preocupação com o conhecimento, principalmente com o pensamento cartesiano, que acabou por desqualificá-lo no âmbito da Filosofia moderna.7

Foucault estabelece, então, um conceito próprio para o que é filosofia: uma forma de pensamento que põe o pensamento em questão e que permite ao sujeito o acesso à verdade, "que tenta determinar as condições e os limites do acesso do sujeito à verdade" (FOUCAULT, 2004, p. 19). A essa forma de fazer filosofia ele chama de "espiritualidade", o conjunto de ações voltadas não para o conhecimento, mas para o sujeito a fim de que se tenha acesso à verdade, incluindo-se nisso exercícios, práticas de purificação, conversões do olhar e mudanças de existência. "Nas práticas da espiritualidade antiga, a verdade, tal como ela é - no sentido de matriz de ações -, pode transformar o sujeito, na medida em que ele sempre é desqualificado para ser fundamento de verdade” (CANDIOTTO, 2010, p. 127).

Ao caracterizar o que vem a ser a espiritualidade segundo essa perspectiva, Foucault leva em consideração que:

1) O sujeito não possui capacidade de verdade. A verdade não é dada de pleno direito ao sujeito como a posse de um conhecimento. Para ter acesso à verdade, é preciso que o sujeito se modifique e se desloque até tornar-se um outro que não ele mesmo. Portanto, a verdade põe em jogo o modo de ser do sujeito.

2) Não pode haver verdade sem conversão do sujeito. Esse movimento (Foucault também usa a expressão "sobrevoo") implica duas modalidades: o movimento do éros e o trabalho da áskesis. Um movimento que o arranca de seu status e que promove uma prática de transformação de si em que o sujeito é o próprio responsável.

3) $\mathrm{O}$ acesso à verdade produz como efeito o retorno ao próprio sujeito, não sob a forma de uma recompensa, mas como algo que o completa e que o transfigura.

\footnotetext{
7 "O imperativo do conhecimento de si configura apenas a aplicação concreta do princípio do cuidado de si". (CANDIOTTO, 2010, p. 127).
} 
Foucault resume essa caracterização da seguinte forma:

[...] para a espiritualidade, um ato do conhecimento, em si mesmo e por si mesmo, jamais conseguiria dar acesso à verdade se não fosse preparado, acompanhado, duplicado, consumado por certa transformação do sujeito, não do indivíduo, mas do próprio sujeito no seu ser do sujeito (FOUCAULT, 2004, p. 21).

$\mathrm{Na}$ antiguidade, a preocupação com o acesso à verdade e a prática da espiritualidade estão inter-relacionadas de tal modo que o cuidado de si designa o conjunto das condições de espiritualidade necessárias ao acesso à verdade. Isso se distingue do paradigma adotado pela modernidade, segundo o qual o sujeito é capaz de ter acesso à verdade porquanto esta, a verdade, é concebida como um modo de conhecimento, que depende de um método e de condições objetivas para se conhecer. Com isso, a modernidade deixa de lado a espiritualidade e adota o caminho do conhecimento como o único acesso à verdade: um caminho indefinido, marcado pela incompletude.

Se definirmos a espiritualidade como o gênero de práticas que postulam que o sujeito, tal como ele é, não é capaz de verdade, mas que a verdade, tal como ela é, é capaz de transfigurar o sujeito, diremos então que a idade moderna das relações entre sujeito e verdade começa no dia em que postulamos que o sujeito, tal como é, é capaz de verdade, mas que a verdade, tal como ela é, não é capaz de salvar o sujeito. (FOUCAULT, 2004, p. 24).

Essa atitude moderna é corroborada por uma teologia fundada no pensamento aristotélico, que adota a racionalidade como sua base teórica e que concebe a fé como um princípio universal. É esse tipo de teologia que estabelece o princípio do sujeito cognoscente.

A correspondência entre um Deus que tudo conhece e sujeitos capazes de conhecer, sob o amparo da fé é claro, constitui sem dúvida um dos principais elementos que fazem [fizeram] com que o pensamento - ou as principais formas de reflexão - ocidental e, em particular, o pensamento filosófico se tenham desprendido, liberado, separado das condições de espiritualidade que os haviam acompanhado até então, e cuja formulação mais geral era o princípio do epiméleiaheautoû. (FOUCAULT, 2004, p. 36). 
Essa mudança se deu de forma lenta, mas não se constitui em um corte arbitrário. Antes, uma relação entre a filosofia do conhecimento e uma espiritualidade que vise à transformação do sujeito por ele próprio estará presente na obra de Espinosa, Kant, Hegel, Schelling, Schopenhauer, Nietzsche, Husserl e Heidegger, na medida em que se procurou vincular o ato de conhecimento a uma transformação no ser do sujeito. É possível atualmente encontrar um ressurgimento das estruturas de espiritualidade até mesmo nos modos de se fazer ciência, não como uma nova forma de religiosidade, mas na maneira de se indagar sobre as condições de acesso à verdade. A preocupação com o que se passa no ser do sujeito, e que se constitui a problematização presente no escopo do marxismo e da psicanálise, envolve características de espiritualidade visto que remete à indagação sobre "o preço que o sujeito tem a pagar para dizer o verdadeiro e a questão do efeito que tem sobre o sujeito o fato de que ele disse, de que pode dizer e disse, a verdade sobre si próprio" (FOUCAULT, 2004, p. 40).

O cuidado de si é, portanto, um princípio que Sócrates vai usar em seu diálogo com Alcibíades que faz parte a uma tradição social, política e econômica, vinculada a um exercício de poder, a uma necessidade de saber e a um sentido de temporalidade e de urgência, que coloca a questão acerca do sujeito, quando indaga sobre que tipo de sujeito é preciso de se ocupar: "o que é este sujeito, que ponto é este em cuja direção deve orientar-se a atividade reflexiva, a atividade refletida, esta atividade que retorna do indivíduo para ele mesmo? O que é este eu?" (FOUCAULT, 2004, p. 50). Essa indagação remete a outra: de que modo o cuidado de si pode conduzir ao conhecimento das práticas para o governo de si e dos outros? O que está em jogo na questão do cuidado de si é a circularidade que vai do eu como objetivo de cuidado ao governo do outro. ${ }^{8} \mathrm{E}$ é isso que estará implicado no pensamento antigo.

\footnotetext{
8 “Ocupar-se consigo é um privilégio, é a marca de uma superioridade social, por oposição àqueles que devem se ocupar dos outros para servi-lo ou ainda se ocupar de um ofício para poder viver". (FOUCAULT, 1970-1982. p. 121).
} 


\section{Conclusão}

A abordagem de Foucault sobre o acesso à verdade como espiritualidade desperta, para a teologia e o cristianismo, a necessidade de uma revisão crítica dos modos de se fazer teologia e de promover uma ação pastoral diante de um mundo que colocou em suspensão todos os saberes construídos. Por essa razão, já não há como tratar das questões emergentes da condição humana e da fragilidade das pessoas neste tempo sem que se coloque no centro do debate os temas que o cristianismo elegeu como aspectos fundamentais, que são aqueles com as quais a teologia e o cristianismo são confrontados.

A abordagem sobre a temática do cuidado de si, tratada em relação ao acesso à verdade no âmbito da teologia, é o que pode oferecer um caminho novo para o fazer teológico e para uma revisão dos modos de afirmação do cristianismo, de modo que contribua para uma ação pastoral voltada para a condição humana em sua realidade vivencial. Esse modo de lidar com a subjetividade pressupõe a compreensão do homem como um ser integral em suas condições concretas de vida. Esse mesmo humano assumido na revelação de Deus na pessoa de Jesus de Nazaré, compreendido na totalidade de suas relações com a criação e com toda a humanidade.

A teologia precisa assumir as incertezas desse tempo e evitar que se construam estruturas de saber e de poder que legitimem as metanarrativas que a pós-modernidade rejeita. Isso significa contribuir para a formulação de uma afirmação da fé que se ofereça como alternativa para a libertação das formas que põe em risco a vida humana. Nesse sentido, não há caminho seguro para a teologia. Uma teologia que não se exponha e não se ofereça para ser questionada e atualizada não tem valor para a sociedade contemporânea. Por essa razão, as vias do testemunho, da comunhão e do serviço, vivenciadas no meio da comunidade, são alternativas válidas para a práxis cristã a fim de que sua mensagem possa ser ouvida em meios às muitas vozes da pós-modernidade. 


\section{REFERÊNCIAS}

CANDIOTTO, Cesar. Foucault e a crítica da verdade. Belo Horizonte: Autêntica, 2010.

CARVALHO, A. F. História e subjetividade no pensamento de Michel Foucault. 2007. Tese (Doutorado). Faculdade de Filosofia, Letras e Ciências Humanas. Universidade de São Paulo, São Paulo.

DELEUZE, Gilles. Foucault. São Paulo: Brasilense, 2005.

FOUCAULT, Michel. A coragem da verdade. São Paulo: Martins Fontes, 2011.

FOUCAULT, Michel. A hermenêutica do sujeito. São Paulo: Martins Fontes, 2004.

FOUCAULT, Michel. A ordem do discurso. São Paulo: Loyola, 2005.

FOUCAULT, Michel. As palavras e as coisas. São Paulo: Martins Fontes, 2002.

FOUCAULT, Michel. Ditos e escritos V: ética, sexualidade, poder. 2. ed. Rio de Janeiro: Forense, 2006.

FOUCAULT, Michel. História da loucura na idade clássica. São Paulo: Perspectiva, 1978.

FOUCAULT, Michel. Le courage de laverité: Le gouvernement de soi et desautres. Coursa u Collège de France, 1983-1984. Éditionétablie par François Ewaldet Alessandro Fontana, par Frédéric Gros. Paris: Gallimard, 2009.

FOUCAULT, Michel. Microfísica do poder. Rio de Janeiro: Graal, 1995.

FOUCAULT, Michel. Qu'est-ce que la critique? Critique etAufklarung. Bulletin de laSocietéfrançaise de philosophie.v. 82, n. 2, abr/jun 1990. p. 36. [Conferência proferida em 27 de maio de 1978].

FOUCAULT, Michel. Resumos dos Cursos do Collège de France(1970-1982). Rio de Janeiro: Jorge Zahar, 1997.

HABERMAS, Jürgen. O discurso filosófico da modernidade. São Paulo: Martins Fontes, 2002.

NIETZSCHE, Friedrich W. A gaia ciência. In: Obras incompletas. 3. ed. São Paulo: Abril Cultural, 1983.

SENELLART, M. A crítica da razão governamental de Michel Foucault. Revista Tempo Social, São Paulo, v. 7 (1-2), p. 1-14, out. 1995. Disponível em: < http://www.fflch.usp.br/sociologia/temposocial/site/images/stories/edicoes/vo712/gover no.pdf > Acesso em: 8 jul. 2013. 